\title{
Higher Mathematics Teaching Based on Core Literacy Training
}

\author{
$X U \mathrm{Hui}^{1, \mathrm{a}}, \mathrm{XU} \mathrm{Wei}^{2, \mathrm{~b}}, \mathrm{XU} \mathrm{He}$ \\ ${ }^{1}$ College of Mathematics and Statistics, Baicheng Normal University, Baicheng,137000,China \\ ${ }^{2}$ Haiming Elementary School,Baicheng,137000, China \\ ${ }^{3}$ Civil Affairs Bureau of Taobei District,Baicheng,137000, China

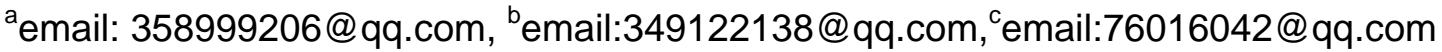

Keywords: Higher Mathematics, Core Literacy, Literacy Training

\begin{abstract}
Higher mathematics takes the core accomplishment as the center to carry on the teaching education reform. Teachers should be aware of the importance and necessity of mathematics literacy to the all-round development of students. Teachers should combine with traditional teaching experience. The core of this paper is to cultivate the students' mathematics literacy and mathematics ability, and to promote the formation and play an important role of the professional and research-based educational ideas of higher mathematics.
\end{abstract}

\section{Introduction}

One of the important basic courses in colleges and universities is higher mathematics, which has strict logic and high application type. Strict abstractness and rich connotation. This requires teachers to have excellent mathematics teaching ability and students' mathematics literacy. This paper combines the traditional teaching experience of higher mathematics. Through the research and practice on the cultivation of students' mathematics literacy and ability, this paper summarizes a lot of key ideas.

\section{Summary of higher Mathematics Literacy}

To develop mathematical literacy, the aim is to make the educated can be based on the basic knowledge and skills of mathematics on the mathematics learning of mathematics with innovation, quality and cultivation. Through the teaching of mathematics, students can take the initiative to explore the mathematical background in mathematics language can be rigorous concise expression, the formation of their mathematical thinking. For the exploration of mathematics always keep innovation and scientific spirit, and can achieve the proposed mathematical concepts and guess the height. Through rational thinking, to solve many problems, phenomena and processes in the real world, using mathematical quantification, simplified way to achieve scientific and rational thought.

The ultimate goal of mathematics literacy cultivation is to promote the educate to obtain comprehensive mathematical quality. The theoretical system of higher mathematics is full of dialectical thinking of theory, such as the dialectical unity between finite and infinite. The logic is between infinity and infinitesimal, the dialectical relationship between continuity and simplicity, etc. Through the study of higher mathematics, students have the correct world outlook, logical thinking and abstract thinking ability. It has the ability to create the world and adapt to the reality. The scientific research of mathematics shows that mathematics draws nutrition from other subjects. Students can acquire the mathematical skills, knowledge and thinking quality needed in scientific research by studying higher mathematics.

Teachers cultivate the mathematics literacy of higher mathematics, students acquire endless new knowledge, through scientific calculation continuously inject vitality into the subject, and with the "Internet" technology, the use of computers. Projector and other equipment, modern teaching mode, make the traditional boring and abstract mathematics teaching image, interesting. Single knowledge structure has fallen behind, teachers should constantly update their knowledge structure. Broaden the field of knowledge, grasp the development trend of mathematics, cultivate suitable professional 
talents for economic construction and social development, and make students become leaders and explorers of economic and social development in the future.

The cultivation of the core accomplishment of higher mathematics is, first of all, from the setting of curriculum objectives, focusing on strengthening psychological quality, exercising willpower, and developing the mathematical foundation of professional courses through the process of learning. Students have independent research and self-study ability, have independent judgment and thinking ability. Second, through the core literacy training, mathematics teaching activities to increase the content of mathematical ideas, through the attention of the method. Students acquire knowledge, understand the dialectical unity of mathematics and life, and learn from formalization to materialization, which highlights the important idea of ideological method teaching. Thirdly, students learn through the curriculum of core literacy. The process of teaching the evolution of mathematical concepts tells students that the concepts in higher mathematics come from practice. A large number of prototypes have evolved into the nature of science through a high degree of abstraction. Students can finally understand the occurrence of mathematical concepts by paying attention to the combination of practice and theory in teaching. Development and the true meaning of archetype. 4th is to adopt the educational method of mathematical modeling and the method of constructing mathematical model of practical problems to form new theories and new ideas of mathematics. From simple to complex learning process, preliminary grasp the method of mathematical model construction, have creative spirit, accumulate experience and ability, and learn to discuss mathematical problems through group discussions, cultivate information. Correct the one-sidedness of learning. 5th, through the establishment of evaluation and assessment system, pay attention to the students' learning effect, pay attention to the change of students' psychology and attitude in mathematics study [1].

\section{The Necessity of Cultivating Core Literacy in Higher Mathematics}

Along with the economic development and the social progress, the education work of our country is continuously improving and improving. Traditional mathematical knowledge and mathematical problem-solving methods are difficult to fully meet the demand. The expression of economy needs modern mathematical concepts, and the solution of economic problems needs more mathematical analysis, therefore, how to be effective. To solve the economic and social phenomena at high speed, it is necessary to cultivate professional talents with good mathematics literacy.

Education plays an important role in the development and growth of a country. Whether it is comprehensive national strength or economic competition, the reform of higher education is imperative. Moreover, we should make great efforts to improve the concept of core literacy, in order to cultivate diverse talents of higher mathematics, have perfect professional skills of higher mathematics, and have the spirit of mathematics. To achieve this goal, it is necessary to reform the curriculum of higher mathematics. Along with the general trend of curriculum reform in colleges and universities, the curriculum system and content of higher mathematics. For example, the adjustment of large class teaching, the compression of class hours, the integration of practical teaching and so on, the goal is to improve the efficiency of mathematics teaching.

Contemporary students, with better observation, understanding and judgment, the cultivation of mathematical literacy, is to cultivate a comprehensive quality of talent to carry out the work. Good mathematical literacy contains a scientific way of thinking. Rational methods, problem-solving practical ability and innovative awareness and so on. Therefore, a comprehensive cultivation of mathematical literacy. It is necessary to reform the teaching mode in the way of thinking and comprehensive quality of students, which requires a process of change and implementation in the process of teaching for both students and teachers[2].

First of all is the teaching method memory reform and the design of the teaching content. Knowledge and skills as the core of teaching training, teachers in the teaching process discuss, talk, ask questions. So that students can have the opportunity to put forward their own views, and active classroom atmosphere, strengthen the intensity of communication, so that students have a comprehensive understanding of themselves, and then promote the generation of motivation for 
learning. To cultivate passion and information, teachers should consciously increase the content of mathematics knowledge background, expand students' learning vision, let the traditional single, preaching into communication, interaction, and with the help of multimedia Internet and other science and technology. Increase the interest of teaching.

Through the reform of the examination method, the evaluation of mathematics teaching is embodied in the goal of promoting the students' all-round development. The students can have a comprehensive understanding of themselves through evaluation and examination. And the evaluation as a screening and screening tools, change the past to use the single model of evaluation with test papers plus the link of self-examination of college students, set up a personalized examination system of students' learning situation, combined with students' homework. Learning experience, test results, self-examination reports, comprehensive evaluation of the learning situation. For the evaluation of teachers, the emphasis is on the professionalism of the team, quality training and other issues. Teachers should be strict in teaching attitude, strengthen the ability of information technology. In addition to having teaching experience and theoretical knowledge, teachers should also have the ability to practice and guide work, and understand the use of teaching psychological guidance skills, so as to achieve a good command. Close the distance between teachers and students[3].

\section{The Ways to Improve the Mathematics Literacy and Mathematical Ability of Higher Mathematics}

In teaching practice, first of all, we should spread the theory of higher learning, on the basis of learning attitude, interest, enthusiasm and effect. Strengthen the teaching on the relevance of the cultivation of students' mathematics ability and mathematics literacy.

For example, in the course of higher mathematics introduction, the teacher should explain the contents of the chapter, draw up the outline for the students, and let the students know the focus and difficulty of the problem . Through the introduction course, the students learn the key and difficult points of the problem . Through the introduction course, the students learn the emphasis of the higher mathematics .

Through the study of the introduction course, the students will actively explore the background and essence of mathematics, form good rational thinking, explore various methods to solve practical problems, and have associative and abstract thinking. It is beneficial to the students' work and study in the future.

The study of the concept of higher mathematics must be carried out around solving practical problems. There are commonalities between practical problems and abstract mathematical theories. Whether it is a geometrical figure or brief calculation, are established to solve practical problems in the process on the basis of the basic theory of these concepts. If compared to the ground, so to solve the problem is the process of building a tall building. The teacher in the teaching concept, to the actual geometric background, introduced the abstract concept for example, the concept of derivative, is related to the limit of the relative rate of change, can be combined with the instantaneous velocity and relative change rate, the abstract problem specific interpretation. Understanding of abstract concepts, and the partial derivative function of two variables of learning, will gradually understand the three calculation methods of triple integral. And gradually the three integral, double integral, integral to contact, the formation of a new understanding of common of the three[4].

For example, the volume of tridimensional is calculated by definite integral, double integral and triple integral. The relation between the three is understood by slice method. The plane cutting area and plane area in the field of space are analyzed concretely.

We know that the integral function of triple integral is equal to 1 . We can calculate the value of triple integral and get the volume of integral region. The volume formula is as follows:

$$
\int_{a} f(x y z) d v=f(x y z) d x d y
$$

At this time, the parallel cross section area in the definite integral is the volume calculation 
formula of the already pointed solid. With the help of slice method, the best understanding of the triple integral is obtained, and the definite integral and double integral are reviewed at the same time. Students' associative thinking, reverse thinking and intuitive thinking are stimulated, and the students' mathematics literacy and ability are improved.

Through the exercise, the higher mathematics can be training and enhance the ability to integrate into higher mathematics. For beginners, a lot of difficulties, problem solving way of the phenomenon is inevitable. As part of the higher mathematics learning exercises, not only do a few exercises, and is the task of teaching practice, review and consolidate the amount of return and supplement of teaching content, practice exercises need to pay attention to is that the students to master the knowledge points, from easy to difficult, therefore, the emphasis and difficulty of the series. The chapter exercises to choose typical, to master the basic knowledge, and then strengthen problem-solving ideas improved. Selection of exercises not only has the depth, but also has the breadth, aims to improve the learning interest of the students. For example the principle of knowledge point median learning, specifically the construction of auxiliary function, and then use the differential mean value theorem of learning, This is the focus of higher mathematics, but students in learning, often feel headache, which requires teachers to better learning plan, let the students master the basic knowledge of the key, then the column title, four operations for derivative, composite function derivative and other related exercises, students are using the intermediate value theorem after the calculation, to learn to use the principle to solve the problem[5].

The study of higher mathematics should be based on the traditional formula calculation and exercise calculus to practice the practical application of mathematics for the students with strong specialty. The arts students are in the study of higher mathematics. It is generally considered boring and boring. So let them realize that the mathematics knowledge can help them to learn. In the teaching content, according to the characteristics of the specialty, some concepts should be simplified. The course of mathematics is supplemented and updated. Mathematical models are established to clarify the significance of major learning mathematics. In spare time, open courses, learning fuzzy mathematics, regression analysis, cluster analysis, and so on. Students learn to use mathematical tools to solve related professional problems. Teachers should also study basic concepts and knowledge, invest time and energy, and select the appropriate application background for scientific research. To meet the needs of the training of new types of talent to carry out the work.

\section{Conclusion}

The reform of higher mathematics education in colleges and universities is aimed at improving students' core accomplishment, which includes innovation, practice, unremitting willpower and psychological quality. This is the sacred mission of mathematics teachers in colleges and universities. The new teaching goal is not high scores, but the cultivation of literacy, which is the development direction of current and future teaching work. Let students basic knowledge, problem-solving methods, form a personalized thinking, can independently and creatively in the future learning and life to solve problems.

\section{Acknowledgement}

In this paper, the research was sponsored by the Educational Science Project of Jilin province during “13th Five-Year Plan” in 2017 (No. GH170603) .

\section{References}

[1] XIE Ying. Constructing a New Model of Higher Mathematics Teaching with the Characteristics of Professional Features - -Taking Higher Mathematics Teaching in Logistics Management Major as an Example[J].Journal of Harbin Vocational \& Technical College,2015,(5):102-103. 
[2] LUO Jing. Discussion on higher Mathematics Teaching from Mathematics Core Literacy[J]. Journal of Shaoguan University, 2017, 38(5):83-85.

[3] WANG Bo. An Analysis of the Cultural implication in the Concept of Limit[J].Journal of Hubei University of Science and Technology,2015,(5):14-16

[4] CHEN Shu. Research on Teaching Reform of higher Mathematics based on Innovation and Entrepreneurship Education[J].Journal of Shandong Institute of Commerce and Technology, 2017, 17(4):75-77.

[5] DING Zhiqiang. Exploration and Analysis on Project Teaching of higher Mathematics in higher Vocational Colleges[J]. Modern Vocational Education,2017,(16):120. 